\title{
ESCOLA NORMAL RURAL NO RIO GRANDE DO SUL: HISTÓRIA INSTITUCIONAL
}

\section{Rural normal school,inRio Grande do Sul: Institutional History}

Flávia Obino Corrêa Werle ${ }^{1}$

\section{Resumo}

Este artigo situa o contexto histórico do Rio Grande do Sul no início da República, articulando a configuração do mundo urbano e o movimento econômico do período; discute iniciativas educacionais da Escola de Engenharia de Porto Alegre, com ênfase nas que tematizavam a formação para 0 meio rural; busca elementos explicativos para interpretar os motivos pelos quais as categorias escola rural e escola normal rural configuraram-se tardiamente no cenário educacional riograndense, finaliza configurando 0 funcionamento de um estabelecimento de ensino de formação de professores para o ensino rural.

Palavras-chaves: Escola normal rural; História institucional; Rio Grande do Sul; Formação professores.

\section{Abstract}

This text situates the historical context of Rio Grande do Sul at the start of the Republic, articulating the configuration of the urban world and the economic movement of the period; it discusses educational initiatives of the School of Engineering of Porto Alegre, putting emphasis on the ones that thematize the formation for the rural milieu. It seeks explicative elements for the motives for the categories rural school and normal rural school being configured at a late date in the educational scenario of Rio Grande do Sul, and it finalizes configuring the functioning of one institution of teaching for the formation of teachers for rural education. ${ }^{1}$

Keywords: Rural normal school; Institucional history; Rio Grande do Sul; Formation of teachers.

Doutora em Educação, professora do Programa de Pós-Graduação em Educação da Universidade do Vale do Rio dos Sinos, Centro de Ciências Humanas, Av. Unisinos, 950, Cristo Rei, CEP: 93020-000- São Leopoldo, RS- Brasil.

E-mail: flavia@helios.unisinos.br 


\section{Metodologia}

O trabalho é uma produção do projeto de pesquisa História dasinstituições escolares: escolas de formação de professores, que dá continuidade à investigação que viemos realizando acerca da história de instituições de formação de professores. Anteriormente analisamos três estabelecimentos de ensino particulares mantidos por congregações religiosas femininas, nos quais funcionou o Curso Complementar. Na atual pesquisa propomos a investigação de três estabelecimentos que objetivavam a formação de professores de primeiras letras para a zona rural. Pesquisar acerca da história de instituições escolares implica na consideração da diversidade de fontes que compõem os arquivos institucionais escolares - artigos jornalísticos tematizando o estabelecimento de ensino, seus professores, alunos, formaturas, inaugurações; livros, diários, plantas de prédios, fotografias, livros de termo e de registros escolares, contratos de trabalho de professores, sumários da história da instituição, convênios e documentos oficiais de integração com outras instituições, dossiês de correspondências, livros inventário, atas, regulamentos, relatórios - bem como entrevistas com ex-professores e depoimentos escritos que tenham sido preservados. Fundamentalmente este texto analisa uma entrevista com professor que atuou na Escola Normal Rural La Salle e alguns materiais escolares bem como documentos sobre a instrução pública - relatórios de presidente de província e falas a assembléia - e estudos sobre o tema do ensino rural e políticas da época.

\section{Cenário Econômico do Rio Grande do Sul}

No início da República, advém, no Rio Grande do Sul, um surto industrial com a instalação, a partir de 1890, de várias indústrias² e a expansão de manufaturas, embora não muito desenvolvidas tecnologicamente, incluindo produtos variados como calçados, farinha, chapéus, confecções, papel e papelão. O panorama internacional, com a crise econômica dos Estados Unidos, em 1893, que provocou a queda no preço do café, trouxe também repercussões para a economia pecuária do estado. No final do século XIX, entretanto, a zona colonial entra em expansão pelo desenvolvimento da lavoura o que se prolonga no inicio do século XX, situação essa favorecida pela primeira

2 Em 1891, foram instaladas no Rio Grande do Sul, a indústria de chocolates Neugebauer e a Companhia de Fiação e Tecidos, em 1894, a Cervejaria Ritter e Filhos, em 1900, a refinaria de banha Otero Gomes, em 1901, a fábrica de pregos Gerdau e, em 1904, a indústria de fogões Wallig. 
guerra mundial, que incrementou a demanda de gêneros alimentícios, concorrendo para o desenvolvimento e comercialização de produtos da lavoura colonial gaúcha. Há também nesta ocasião, o desenvolvimento da lavoura arrozeira que conquista o mercado nacional. É um período (entre 1914 e 1918) de nova expansão industrial com a implantação de fábricas de banha, vinho, cervejas e têxteis, e de frigoríficos no estado. O desenvolvimento do setor primário e secundário que ocorria no Rio Grande do Sul sofreu, entretanto, o impacto da retração econômica do pós-guerra, momento em que a pecuária entra em crise. Esta se agrava ao longo dos anos 20 com a redução dos abates nas charqueadas, chegando à paralisação dos frigoríficos. Assim, no final dos anos trinta do século XX, com a acentuação das crises da pecuária, da lavoura colonial - decorrente do baixo nível tecnológico -, e a decadência das charqueadas, intensifica-se o êxodo rural. Desta forma, no final do Estado Novo, o impacto na organização da população no espaço das cidades se fazia sentir no Rio Grande do Sul, quando se instala uma política de conter o êxodo rural, pois a sociedade urbano-industrial se instalava e os problemas dela decorrentes não estavam equacionados. O Rio Grande do Sul, nos anos 50, era "0 estado que mais população emigrante fornecia para outros estados, enquanto que era também a unidade da federação que menos brasileiros recebia" (PESAVENTO, 1994, p. 124). As grandes propriedades rurais excluíam a massa de trabalhadores que migrava do campo, concentrando-se nas cidades, compondo as periferias urbanas, em busca de trabalho. É este contexto socioeconômico das primeiras décadas do século XX que se configura, no cenário educacional brasileiro, o ruralismo pedagógico segundo Catani, Vicentini e Lugli (1997), que visava a fixação do homem no campo, acentuava o sentido rural da nação brasileira e identificava o currículo como uma forma de promover esta valorização e a fixação ao mundo rural, prevenindo o êxodo para zonas urbanas. Foi um momento de diferenciação de políticas educativas pela configuração de programas de ensino voltados para as lides rurais o que também se fez sentir na formação de professores (CATANI; CÂMARA BASTOS, 1997).

\section{A Instrução Pública junto a Populaç̧ões Rarefeitas}

Durante o período imperial "as grandes propriedades, as distâncias e 0 pequeno número de vilas" de acordo com Almeida (1989, p. 76) eram os motivos alegados pelas autoridades para o pequeno número de escolas primárias estabelecidas no território brasileiro. As políticas públicas, embora não declarassem explicitamente, consideravam as dificuldades decorrentes da extensão territorial e não estabeleciam metas, como a instrução escolar elementar para toda a população dispersa no vasto território nacional. A obrigatoriedade, no final 
do terceiro quarto do século XIX, vigia apenas para crianças e indivíduos sem instrução que residissem nas proximidades de um estabelecimento de ensino (ALMEIDA, 1989, p.144). Por outro lado, os mestres preferiam ensinar em centros urbanos e a proposta dos governantes não passava da intenção de disseminar pequenas escolas normais nas cidades de segunda classe

A falta de respeito à lei decorre da insuficiência de instrução que é dada à população rural; e a causa desta insuficiência é a carência de bons institutores. Os mestres que têm instrução adequada e aptidões para ministrar um bom ensino encontram facilmente condições mais vantajosas nos grandes centros e, porisso, são os menos capazes que se fixam nos campos, obrigados a viver, a morar no meio das populações rurais. Conviria, para remediar esta inconveniência, fundar pequenas escolas normais nas cidades de segunda classe, escolas que, dando instrução nas aldeias e vilas situadas em um determinado espaço, receberam alunos-mestres que as municipalidades enviariam às suas expensas. As municipalidades fariam um contrato de compromisso pelo qual, ao terminar o curso normal, os alunos-mestres voltariam a desempenhar as funções de institutores no município de origem (ALMEIDA, 1989, p. 296. Grifo nosso)

A grande extensão territorial e a população rarefeita eram os motivos das dificuldades da extensão da instrução pública elementar no período imperial o que acentuava o descaso e desconsideração pela população rural de poucos recursos. Para atender à instrução na zona rural, as Assembléias Provinciais também discutiam a possibilidade de organizar um corpo de professores ambulantes que percorressem aldeias e vilas ensinando em zonas mais afastadas, o que não teve efeito prático (ALMEIDA, 1989, p. 297).

O poder público, para não inflacionar os gastos com a instrução, apenas mantinha escolas quando houvesse um número mínimo de alunos freqüentes, o que fazia com que as escolas públicas fossem instaladas a uma boa distância umas das outras, especialmente em distritos com pouca população. Em zonas coloniais, por este motivo, por questões religiosas e pelo fato do ensino ser ministrado na língua dos imigrantes, multiplicavam-se as escolas particulares, as quais, em concorrência com as públicas, diminuíam a freqüência destas. A organização das escolas de zona rural era diferenciada das de zonas mais populosas onde, havendo mais recursos e maior número de professores, era possível práticas tradicionais de ensino, possibilitando manter aulas separadas para meninos e para meninas o que dificilmente ocorria em aulas públicas situadas em localidades mais distantes onde eram admitidas as aulas mistas. Esta situação não ocorria apenas no Rio Grande do Sul. No Piauí, por exemplo, a adoção de escolas mistas era considerada inovação e medida de economia, entretanto, não era adotada generalizadamente, mas apenas em 
lugarejos e locais marginais na estrutura hierárquica de escolas públicas (LOPES, 1999, p. 96).

Por outro lado, a administração da instrução pública admitia exigências menores em aulas de zonas rurais, no que se refere à freqüência dos alunos, ao preparo dos professores e aos conteúdos a serem ensinados (WERLE, 2004).

O trecho a seguir transcrito de um relatório de inspetor escolar do Rio Grande do Sul, datado de 1897, bem exemplifica a menor exigência ${ }^{3}$ com relação ao ensino em zonas rurais

E como adiantamento a estes conceitos, me permitireis transportar para aqui as seguintes palavras do dr. Mariano Pereira Nunes, proferidas numa conferência realizada por ele na vizinha Republica Oriental do Uruguai, em 1892, e perfeitamente adaptadas às nossas condições: 'A campanha precisa um programa especial para as suas escolas, completamente diferente do das urbanas, pelas seguintes razões:

Primeira: $\mathrm{O}$ meio diverso em que se desenvolve a inteligência das crianças. Segunda: A classe de vida para que se tem que preparar.

Terceira: A maior necessidade que têm os pais do serviço de seus filhos. Quarta: A distância em que pode estar a escola.

Quinta: Os obstáculos que apresenta na campanha a inclemência dos elementos naturais.

Sexta: O pouco preparo de muitos pais para compreenderem os benefícios da instrução e animarem seus filhos para aproveitá-los.

Sétima: $O$ interesse que há, em generalizar a instrução, em menor grau, em todos os pontos da campanha.

Oitava: A dificuldade que oferece a alimentação das crianças na escola.

Nona: A natural distribuição dos trabalhos rurais (MOACIR, 1939, p.79).

Este trecho denota preconceito para com a população residente em zonas rurais e para com o trabalho que realizavam, bem como aceitação do envolvimento infantil precoce no trabalho rural, naturalizando essas relações de trabalho pela inclusão da criança como mão de obra.

Embora a classificação em entrâncias denote a importância da escola valorada em relação aos centros mais populosos e, mesmo que as escolas mais distantes dos centros urbanos fossem mais numerosas que as situadas em

3 Não apenas no Rio Grande do Sul esta situação se verificava, mas era comum também em outras províncias, como registrado no ano de 1848 na Bahia, quando estava em discussão a proposta de dividir a instrução primária em duas classes, uma de instrução primária elementar propriamente dita e outra de segunda classe com um programa de ensino mais avançado. A proposta era estabelecer aulas de primeira classe em vilas e lugares menos importantes e as de segunda, em vilas e cidades mais populosas (MOACYR, 1939, p. 79). 
núcleos mais densamente habitados, a referências privilegiam os padrões de funcionamento em relação aos estabelecimentos de ensino situados nos núcleos residenciais das cidades mais populosas. Desta forma levantamos a hipótese de que a política educativa no período imperial era de omissão em relação à necessidade de instrução pública para populações pouco densas de distritos rurais e de privilegiamento de escolas e professores de centros urbanos. Por outro lado, em decorrência da restrita sistematização que o conhecimento pedagógico alcançava na época, da invisibilidade do contexto rural como demandante de práticas e políticas de administração da educação propositivas para as populações não urbanas, da pouca importância dada ao setor rural visto como composto por populações pobres às quais qualquer mínimo de instrução bastava, e da ausência de acumulação de recursos financeiros suficiente que possibilitasse ao setor público arcar com a disseminação da instrução e ampliar seu aparato de controle por todo o seu território, a categoria formação do professor para a zona rural não havia se configurado. Pode-se afirmar que no final do século XIX a instrução pública no Rio Grande do Sul não havia ainda identificado e diferenciado, com positividade e clareza, a escola rural. No âmbito das políticas havia uma instrução pública para estas populações, mas na modalidade de cópia empobrecida da educação ofertada para os residentes em zonas mais urbanizadas.

Muito custará conseguir-se o provimento [com professores] das escolas rurais, para as quais dificilmente se encontrarão candidatos que reúnam toda a competência, justamente exigida pela lei, mas não remunerada com proporcional justiça. Seria, por isso, bom, contentarmo-nos com os que sabem ensinar os principais rudimentos de que necessitam os meninos pobres da campanha, e parece-me 0 suficiente, pois que os ricos, que podem, e devem instruírem-se melhor, não freqüentam as escolas rurais. (Inspetor escolar, Manoel Pinto da Costa Júnior. 1987, Grifo nosso).

As formas com que a educação rural e seus agentes eram referidas educador das colônias, professorado da campanha, ensino popular, distritos de fora, meninos pobres da campanha, distritos rurais, escolas da campanha, escola rural, zona colonial, meio rural - acenavam para ambigüidade, desprestígio e desconsideração de suas características nos regulamentos para a instrução pública no estado (WERLE, 2004).

Os dados referentes ao quantitativo de escolas bem indicam a predominância das situadas fora de centros urbanos. Apenas para exemplificar, em 1898, em quatro das regiões escolares que organizavam a instrução pública no Rio Grande do Sul, as escolas estavam assim distribuídas: 
Escola normal rural no Rio Grande do Sul: história institucional

\begin{tabular}{|c|c|c|c|c|c|c|c|c|}
\hline $\begin{array}{lr}\text { No. } & \text { de } \\
\text { escolas por } \\
\text { entrância } \quad \text { e } \\
\text { região } \\
\text { escolar }\end{array}$ & $\begin{array}{l}\text { 1. }^{a} \text { Região } \\
\text { Escolar }^{4}\end{array}$ & $\%$ & $\begin{array}{l}2 .^{a} \quad \text { Região } \\
\text { Escold }^{5}\end{array}$ & $\%$ & $\begin{array}{l}3^{a} \quad \text { Região } \\
\text { Escolar }^{6}\end{array}$ & $\%$ & \begin{tabular}{|l}
$4 .^{a} \quad$ Região \\
Escolar
\end{tabular} & $\%$ \\
\hline $3 .^{a}$ entrância & 37 & $40 \%$ & 0 & & 0 & & 0 & \\
\hline 2. ${ }^{\mathrm{a}}$ entrância & 15 & $16 \%$ & 8 & $6 \%$ & 0 & & 14 & $10 \%$ \\
\hline 1. ${ }^{a}$ entrância & 41 & $44 \%$ & 128 & $94 \%$ & 119 & $100 \%$ & 129 & $90 \%$ \\
\hline Total & 93 & & 136 & & 119 & & 143 & \\
\hline
\end{tabular}

Considerando que as escolas de 1. ${ }^{\text {a }}$ entrância eram as mais afastadas de zonas urbanas e que as de 3. entrância eram das cidades e centros mais populosos, constata-se a predominância das escolas de zonas mais distantes e menos habitadas.

Esta situação segue no início do século XX, quando as estatísticas da educação no estado apontam que três-quartos das escolas elementares eram rurais, conforme dados de 1906. Por outro lado, sendo restritos os recursos para a educação a alternativa de subvencionar escolas particulares era bastante adotada. Em 1913, por exemplo, o Relatório do Presidente da Província, registra que a instrução pública dividia-se em urbana e rural sendo, a primeira, ministrada na Escola Complementar, em Colégios Elementares e Escolas Isoladas e, a segunda, em Escolas Subvencionadas. O regime das subvenções às escolas municipais e particulares, continuava o Presidente, estava produzindo ótimos frutos que se concretizavam na maior difusão do ensino rural, na efetividade do ensino da língua portuguesa nas escolas particulares, especialmente na região colonial, com a facilidade do provimento definitivo das escolas por pessoal de comprovada competência.

Portanto, verifica-se de maneira geral uma desatenção para com a zona rural no atendimento escolar e sua invisibilidade no âmbito das políticas públicas, bem como um discurso de desqualificação da mesma frente à zona urbana. Pode-se, ao lado destas questões históricas, levantar a hipótese de que as características que Julia Varela identifica como constituintes dos sistemas educativos foram se articulando diferentemente com relação à zona rural, como que produzindo tal invisibilidade.

4 Compunham a 1. ${ }^{a}$ região escolar: Porto Alegre, Viamão, Dores de Camaquã, São João de Camaquã.

5 Compunham a 2. ${ }^{\text {a }}$ região escolar: São Leopoldo, Taquari, São Sebastião do Caí, Santo Antonio da Patrulha, Torres, Conceição do Arroio, Gravataí.

6 Faziam parte da 3. r região escolar: São João de Montenegro, Bento Gonçalves, Caxias, Vacaria, Lagoa Vermelha, Alfredo Chaves, Lajeado, Estrela, Taquari, Triunfo, São Jerônimo.

7 Os seguintes municípios compunham a 4. ${ }^{a}$ região escolar: Santa Maria, Cachoeira, Rio Pardo, Caçapava, Santa Cruz, São Vicente, São Sepé, Lavras, Encruzinhada, Santo Amaro, Venâncio Aires, São Martinho, São Francisco de Assis. 
Júlia Varela (1986), em sua genealogia dos sistemas educativos, indica quatro condições para a constituição dos sistemas públicos de educação: a compreensão da infância como fase separada do mundo adulto, a institucionalização da escola, a constituição de um corpo de especialistas e a imposição da escola pela substituição de outras agências de socialização. Pela necessidade da mão-de-obra infantil no campo, pode-se levantar a hipótese de que foi mais difícil a visualização da criança de outra forma que não como um adulto em miniatura a qual, mesmo pequena, podia ir atuando no mundo produtivo, assumindo pequenos trabalhos e, portanto, mais lento o processo de compreensão do mundo infantil como separado do mundo do adulto. Esta indiferenciação da infância do meio rural e sua introdução acelerada e temporã no mundo adulto pelos trabalhos ${ }^{4}$ que realizava não conduzia ao entendimento da necessidade da escola como um espaço separado do mundo da vida, um local especial no qual as crianças deveriam ser educadas e preparadas. A família dava conta da educação e da formação para a vida, provendo o que era necessário à sua inserção no meio rural. Assim, a constituição de professores como profissionais especialistas no trato das crianças cujos conhecimentos se forjavam no espaço da escola, local de educação da infância, era também postergada com relação à zona rural.

A especialização dos professores é, para Varela, uma forma de prover conhecimentos e inculcar valores e hábitos necessários à ordem social, possível a partir da constituição da infância como algo diferente e à parte do mundo dos adultos, e constituída em locais especialmente eleitos para isso, nos quais foram sendo produzidos os conhecimentos específicos sobre 0 ato de educar. Ora, se a criança no meio rural era considerada como mão-de-obra em potencial, muito cedo incorporada nos trabalhos agrícolas, se a família assumia o ensinamento necessário para o trabalho e a vida na zona rural, se 0 espaço da escola separado da vida das lides do campo não era valorizado, todos estes elementos levam à conclusão de que o sistema educativo se configura, no mundo rural, tardiamente.

Portanto, as condições referentes ao ensino em distritos rurais foram, conforme indicam nossos estudos, lentamente sistematizados e conceptuados ao ponto de, apenas nos anos 40 do século XX, se configurarem as ações especializadas de formação de professores para a zona rural, no âmbito do sistema educativo. Ou seja, havia uma indiferenciação nas práticas de instrução pública da época seja em decorrência da restrita sistematização e ambigüidade que o conhecimento pedagógico necessário ao mundo rural apresentava, seja pela pouca importância dada a este setor

\footnotetext{
${ }^{8}$ Na zona da colônia desde cedo as crianças ajudavam na ordenha, na colheita, no fabrico de queijo e em outras tantas tarefas fundamentais à vida rural.
} 
visto como composto por populações pobres às quais uma instrução mínima era suficiente, seja pela ausência de acumulação suficiente que possibilitasse ao estado arcar com a disseminação da instrução pública e ampliar seu aparato de controle por todo o seu território, do que resultava a invisibilidade de necessidades, características, requisitos e normas específicas para a instrução em distritos rurais.

Dando um salto no tempo, considerando a década de vinte do século $\mathrm{XX}$, registramos indícios de uma incipiente pressão - que é considerada por Arelaro (1980, p. 75) como "tentativas de orientação intervencionista do Estado Liberal" - para a separação entre as instâncias do poder público. Surgiram "em várias cidades as "ligas de combate ao analfabetismo", inspiradas na Liga de Defesa Nacional (1916)... (e) materializaram o 'entusiasmo pela educação' empunhado pela burguesia da época” (GUIRALDELU Jr., 1986/1987, p.3). Com base na divisão administrativa do estado, sugeria-se que o encargo da instrução rural e suburbana fosse das municipalidades e que, os professores, a exemplo dos estaduais e federais, fossem bem remunerados (MEIRELLES, 1920). Com o intuito de combater o analfabetismo e difundir a cultura cívica, o município deveria dotar a instrução municipal de uma organização e fiscalização capaz, elevando também os vencimentos dos professores e construindo casas adequadas para escolas rurais e suburbanas. A instância federal, nos anos trinta, adota a estratégia de criação de um organismo de caráter nacional para coordenar o ensino primário: a Comissão Nacional de Ensino Primário a qual competia a articulação das três instâncias do poder público para o combate ao analfabetismo e integral nacionalização do ensino primário, a diferenciação entre o ensino de zonas urbanas e rurais, a estruturação do currículo primário, o dimensionamento da obrigatoriedade escolar e gratuidade do ensino primário, a carreira do magistério primário, a posição do ensino religioso dentre outros assuntos. Era uma comissão com funções normativas, ao definir entendimentos sobre obrigatoriedade, currículo, gratuidade e, com funções operativas, frente aos dois elementos polarizadores da época, o analfabetismo e a nacionalização (BRASIL, Decreto Lei n. 868, 1938).

\section{Formação da Mulher e do Operário para o Meio Rural}

Faz-se necessária alguma referência a iniciativas levadas a efeito pela escola de Engenharia de Porto Alegre quanto à formação da mulher para 0 meio rural e à formação de operários para as lides agrícolas. Estes dados, embora não diretamente ligados à formação do professor para a zona rural, informam acerca de como a temática rural era tratada em iniciativas do poder público do estado. 
A Escola de Engenharia de Porto Alegre fundada no ano de 1896, objetivando o preparo de profissionais para uma nova ordem urbano-industrial no estado, constituía-se de um complexo de instituições educativas de vários níveis de formação técnico-profissional. Dentre seus institutos, dois merecem destaque tendo em vista o foco deste estudo, quais sejam o Instituto Pinheiro Machado que formava operários rurais e o Instituto de Educação Doméstica e Rural. Esta ultima instituição funcionou em Porto Alegre, onde hoje está situada a Faculdade de Arquitetura da UFRGS, entre 1920 e 1934, com interrupção nos anos de 1932 e 33, fornecendo um ensino totalmente gratuito a "condutoras de trabalhos domésticos rurais" segundo Godoy (1999), organizado em dois cursos, um elementar, de quatro anos, e um técnico, de três anos. Especialmente neste último compunham o currículo além de disciplinas propedêuticas, outras voltadas para a formação rural tais como jardinagem e pomicultura, laticínios, sericultura, apicultura, víveres e alimentos, dentre outras.

O Instituto Pinheiro Machado visava "o adestramento, para os serviços agrícolas" dos meninos sem recursos, oriundos de todos os pontos do estado, principalmente de zonas rurais. $\mathrm{O}$ instituto destinava-se às classes pobres, recebendo os menores matriculados, roupa, pensionato e ensino gratuitos. O curso de operários rurais era feito em 4 anos de estudos e trabalhos práticos, podendo o aluno ser analfabeto, ao ingressar no primeiro ano. 0 ensino teórico era considerado equivalente ao de uma escola primária-elementar, abrangendo educação moral e cívica. O ensino profissional compreendia as práticas necessárias a um operário rural, tais como trabalhos de horta, lavoura, pomar, jardim e abrangendo ainda o ensino prático de certos ofícios que se relacionam com a vida rural, como sejam os de ferreiro, carpinteiro e seleiro. Especial atenção deveria ser dada à cultura física dos menores matriculados, sendo ela ministrada por meio de exercícios metódicos e progressivos de ginástica sueca, escotismo, exercícios militares e jogos esportivos ao ar livre.

Portanto, constata-se que a Escola de Engenharia focava em alguns de seus institutos a formação rural, mas em nenhuma de suas instituições propunha a formação de professores nem a formação de professores para a zona rural.

Nos anos trinta, em decorrência da revolução, a crise financeira atingiu a Escola de Engenharia, momento em que ocorreu, também, um movimento para sua anexação à Universidade de Porto Alegre. Isso de fato ocorre no ano de 1934, quando se integram a Escola de Engenharia e a Universidade de Porto Alegre. Esta anexação traz, como conseqüência, a desarticulação do antigo complexo, passando os cursos técnicos, elementares e básico para a administração do estado. 


\section{Ruralismo Pedagógico}

No final dos anos vinte e inicio dos trinta constitui-se o discurso de combate ao urbanismo e valorização da escola rural como campo de experiência e ensaio de processos agrícolas modernos, um discurso de diferenciação entre a escola de zona rural, de zona urbana e de zonas litorâneas.

Dentre as 112 teses apresentadas na I Conferência Nacional de Educação realizada em Curitiba, em 1927, pelo menos três estavam diretamente ligadas ao ensino agrícola; nelas estava expressa a importância do reconhecimento do vinculo entre a educação agrícola e a permanência da população no campo. Eram teses que falavam da urgência da "ressurreição agrícola no Brasil" de acordo com Penna (1927) citado por Costa, Shena e Shmidt (1997) e que o rumo do campo deveria ser a preocupação máxima dos dirigentes. Ferreira Filho detalhava, em sua tese n. 58, a importância do ensino agrícola prático em escolas rurais defendendo que as noções de agricultura deveriam ser incorporadas ao programa das matérias das escolas normais. Entretanto, é na tese n. 34, defendida por Deodato de Moraes que a argumentação se explicita e focaliza na educação básica, por ele chamada de popular:

É na escola popular que devem nascer a tradição agrícola e o prestigio do trabalho da roça. É ela que tem de dar combate renhido à rotina industrial e comercial, agrícola, pastoril, extrativa e manufatureira, por uma instrução aprimorada e eminentemente prática, que ensine a explorar os campos, a adubar a terra, a descobrir as águas, a criar gado, ave, abelha, a fazer queijo e manteiga, a extrair, preparar, armazenar e vender o que a natureza dá ao trabalhador humilde mais incansável. Cabe à escola propagar as noções que correspondem às necessidades sociais e econômicas da população rural... (MORAES, 1997, p.195).

Da mesma forma, Sud Mennucci, em 1934, defendia, insistentemente, a formação diferenciada para o meio rural frente à ofertada no meio urbano:

Temos de separaro ensino das cidades do ensino dos meios rurais e do ensino da zona litorânea. É mister diferenciá-los quanto à sua orientação e ao seu alcance, cindi-los para que produzam três mentalidades absolutamente diversas e que, no entanto, reciprocamente se complementem para o equilíbrio social do organismo nacional. Em ultima análise, temos de criar, com características próprias e intrínsecas , o homem da cidade, o homem do campo, o homem do mar. E criá-los sem que um inveje a sorte do outro e se julgue em plano inferior na escala social (MENNUCCI, 1934, p. 188). 
É nítida a intencionalidade de diferenciação entre cidade e campo e a associação da prática de campo a um tipo específico de formação de professores. Nesse contexto de valorização e idealização da escola e da educação rural que se instalam as escolas normais rurais.

\section{Escola Normal Rural}

Estas teses e argumentos floresceram no final da terceira década do século XX, mas mesmo assim poderíamos afirmar que as condições referentes ao ensino em distritos rurais foram, tardiamente tematizados nas políticas educacionais, a ponto de, no Rio Grande do Sul, apenas no final da quarta década do século XX, se instituírem os cursos normais rurais. Em 1943, o RGS contava com três Escolas Normais Rurais da Arquidiocese, em Porto Alegre, a La Salle em Serro Azul, hoje, Cerro Largo, e Escola São José do Murialdo em Caxias. A Escola Normal Rural La Salle, masculina, funcionou entre 1941 e 1972, com um currículo especializado para a formação de professores para o ambiente rural. Em fevereiro de 1958 foi criada uma Escola Primária Rural, anexa à Escola Normal Rural. Os alunos da Escola Normal eram enviados pelas prefeituras de municípios vizinhos com o objetivo de serem formados professores rurais, eram, em geral, filhos de pequenos agricultores e proprietários rurais.

Quanto à formação do professor para a zona rural destacava a diferenciação e objetivos de formação Mennucci:

Assim se explica minha insistência pela criação das Escolas Normais Rurais, formadoras do mestre com consciência agrícola, conhecedor das necessidades da agricultura, a cavaleiro de seu meio como cultura e como nível mental, capaz de vulgarizar a ciência e pô-la em evidencia pelos resultados imediatos. Será do mesmo passo um conhecedor das inferioridades locais, um defensor incansável do nível médio da higidez coletiva, através de sua experiência individual. E será um pregador sistemático da necessidade da fixação do homem à terra e da formação das sociedades perfeitamente integradas ao seu meio, produtos das determinantes geográficas a reagir sobre as características biologias (MENNUCCI, 1934, p. 202).

No início do século XX, instaura-se um momento de visibilidade da escola rural e um movimento de inclusão na legislação de elementos que demonstram sua consideração.

A Escola Normal Rural La Salle, masculina, tinha seu currículo organizado para atingir o objetivo de formar professores para o ambiente rural. Para que a identificação com o campo se configurasse, era necessário conhecer agricultura - o estudo da terra como suporte e como condição de vida de 
todos os seres - e zootecnia, esta voltada para o trato dos animais domésticos em geral, incluindo a suinocultura, bovinocultura, eqüinocultura, dentre outros animais. Os estudos também abrangiam a agricultura especial, que estudava as plantas em particular, como o arroz, o feijão, o milho, o trigo e a soja. Fazia parte também do curnículo o ensino de adubação, química do solo, conservação do solo e sua recuperação. Eram da mesma forma contempladas informações acerca dos cuidados necessários com o desmatamento, e estudos acerca das águas hídricas, pluviais e as nascentes. Embora o termo não fosse utilizado na época, a formação de professores ministrada na Escola Normal Rural em estudo demonstrava nítida preocupação "ecológica".

Essa gente [rapazes, alunos da Escola Normal Rural La Salle], eles iam nas escolas rurais, que os alunos são filhos de agricultores, no meio da colônia, com o objetivo não de retirá-los do ambiente rural, mas de fazer entender como agir com a natureza, com a terra, com a plantação, seleção de sementes, aplicação de adubos orgânicos, o conhecimento pelo menos elementar da adubação química. São assuntos assim, extremamente variáveis, porém de extrema importância (entrevista com professor da Escola Normal Rural La Salle).
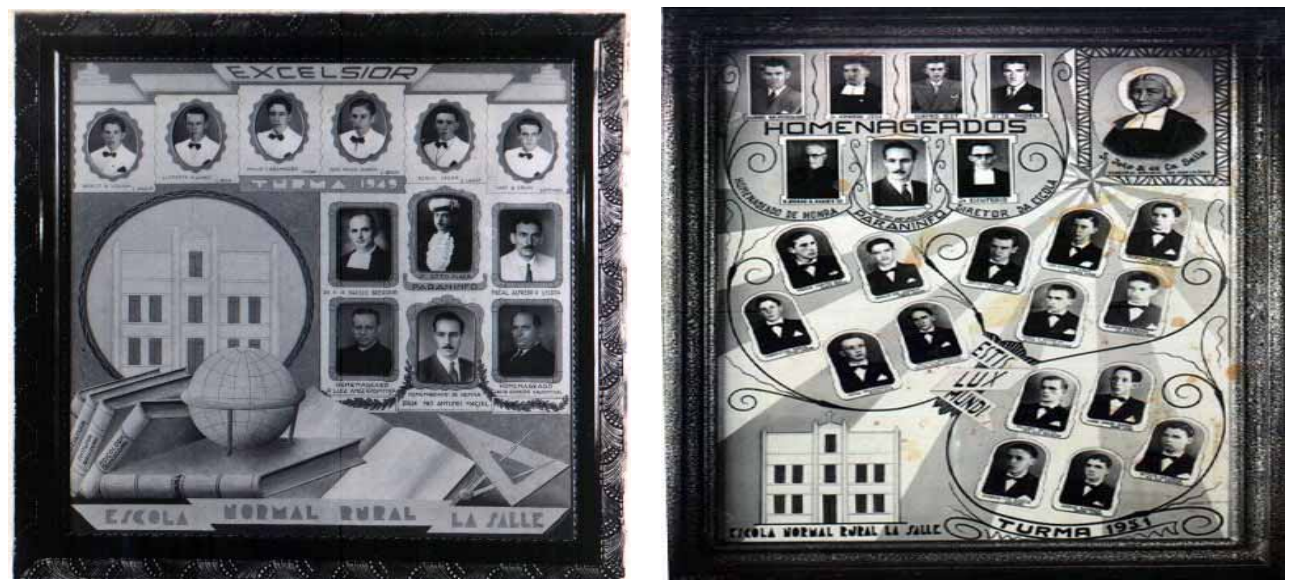

No ano de 1947, a primeira turma de formandos, 13 alunos, concluiu o curso, entretanto, até o momento, apenas obtemos fotografias referentes aos formandos dos anos de 1949, 1951 e 1952.

Estes quadros de formatura apresentam em destaque o prédio da escola, o que é incomum no conjunto de quadros de formatura que tenho analisado em minhas pesquisas. A evidência dada ao prédio pode ser atribuída ao fato de que o mesmo foi construído especialmente para abrigar a referida escola. Ressaltamos também a ausência, nos quadros de formatura, de 
figurativos e de referência nos lemas ao mundo rural, embora o mundo científico e da escola esteja presente pelos livros, globo, esquadro, conforme se pode ver. Os lemas dos referidos quadros acenavam para o papel de destaque que os formandos deveriam desempenhar como profissionais.

\begin{tabular}{|c|c|c|c|c|}
\hline $\begin{array}{l}\text { Nome do } \\
\text { estabelecimento }\end{array}$ & Ano & $\begin{array}{l}\text { Registros escritos } \\
\text { constantes dos quadros } \\
\text { de formatura }\end{array}$ & $\begin{array}{l}\text { Lema escrito no } \\
\text { quadro de } \\
\text { formatura }\end{array}$ & Tradução do lema \\
\hline \multirow[t]{3}{*}{$\begin{array}{l}\text { Escola Normal Rural } \\
\text { La Salle }\end{array}$} & 1949 & $\begin{array}{l}\text { Escola Normal Rural La } \\
\text { Salle. Excelcior. Turma } \\
1949\end{array}$ & Excelsior & Mais ao alto. \\
\hline & 1951 & $\begin{array}{l}\text { Escola Normal Rural } \\
\text { La Salle. Turma } 1951 .\end{array}$ & Estis lux mundi & $\begin{array}{l}\text { Sois a luz do } \\
\text { mundo. }\end{array}$ \\
\hline & 1952 & $\begin{array}{l}\text { Escola Normal Rural La } \\
\text { Salle .Turma } 1952\end{array}$ & $\begin{array}{l}\text { Onde estiver a } \\
\text { verdade lá } \\
\text { estaremos. }\end{array}$ & \\
\hline
\end{tabular}

A Escola Normal La Salle funcionava como internato para alunos residentes em cidades distantes como os que vinham de São Sepé, Livramento, Dom Pedrito, Gravataí, Porto Alegre, Novo Hamburgo. Sendo mantida pela ordem religiosa dos irmãos Lassalistas havia inicalmente apenas três professores leigos. A ação destes professores não se restringia ao tempo de aulas, mas organizavam jogos e momentos de recreação e interação esportiva para os alunos. O professor entrevistado, por exemplo, incentivou a prática de vôlei, basquete, futebol entre os alunos.

A Escola Normal Rural se diferenciava da Escola Complementar esta mais dirigida para filhas de famílias abastadas, de cunho fortemente propedêutico e desenvolvendo a prática em escolas elementares de aglomerados urbanos - pelo esforço de contemplar a cultura do homem do campo e estruturar uma formação prática para o meio rural.

Foi em 1954, com a reorganização do Ensino Normal no estado, por meio da Lei n. 2.588 de 25 de janeiro de 1955, que as Escolas Normais Rurais tiveram que alterar seu regime escolar e estrutura, passando a ser denominadas de Escolas Normais Regionais, ao lado de outros estabelecimentos de formação de professores como a Escola Normal e o Instituto de Educação. As Escolas Normais Regionais transformadas poderiam, atendendo às peculiaridades do meio em que se situavam, e às suas finalidades específicas, dar maior desenvolvimento aos estudos e técnicas que interessassem à vida rural. 


\section{Referências}

ALMEIDA, J. R. P. de. História da Instrução Pública no Brasil (1500-1889). São Paulo,SP: EDUC, Brasília, DF: MEC/INEP. 1989.

ARELARO, Lisete Regina Gomes. A Descentralização na lei 5692/ 71: coerência ou contradição? 205 f. 1980. Dissertação (Mestrado em Educação) Faculdade de Educação, Universidade de São Paulo, 1980.

COSTA, Maria Jose Franco Ferreira de; SHENA, Denílson Roberta; SCHMDT, Maria Auxiliadora. In: CONFERENCIA NACIONAL DE EDUCAÇÃO, 1, Brasília, DF. Anais... Brasília,DF: INEP, 1997, p. 622-625

COMPAGNONI, Ivo Carlos. História dos Irmãos Lassalistas no Brasil. Canoas: La Salle, 1980.

CATANI, Denice Bárbara; VICENTINI, Paula Perin; LUGLI, Rosário Genta. A profissionalização e as práticas de organização dos professores: estudos a partir da imprensa periódica educacional. In: CATANI, Denice; CÂMARA BASTOS, Maria Helena (org) Educação em Revista: a imprensa periódica e a História da Educação. São Paulo, SP, p. 77-91, 1997.

FERREIRA FILHO, João Cândido. Ensino agnícola nas escolas primárias rurais. In: COSTA, Maria Jose'Franco Ferreira de, SHENA, Denílson Roberta, SCHMIDT, Maria Auxiliadora. I Conferencia Nacional de Educação, Curitiba, 1927. Brasília, DF: INEP, 1997, p.338-342.

GODOY, LetíciaA Azambuja. OInstituto de Educação Domésticae RuraldaEscola de Engenharia de Porto Alegre: uma escola-lar (1920-1931). (Dissertação de Mestrado) - Programa de Pós-Graduação em Educação, UFRGS. Porto Alegre, 2000.

GUIRALDELU JR, Paulo. A Evolução das idéias pedagógicas no Brasil Republicano. Didática, São Paulo, SP, n. 22-23, p. 1-15, 1986/1987.

LOPES, Antonio de Pádua Carvalho. Imagens do masculino e do feminino: coeducação e profissão docente no Piauí (1874-1910). In: FARIA FILHO, Luciano Mendes (org). Pesquisa em história da educação: perspectivas de análise, objetos e fontes. Belo Horizonte: HG, p. 95-110. 1999.

MENNUCCI, Sud. A crise brasileira de educação. 2. ed. São Paulo, SP: Piratininga, 1934.

MOACYR, P. A instrução e as províncias (subsídios para a história da Educação no Brasil) 1834 - 1889. Espíito Santo, Minas Gerais, Paraná, Santa Catarina, Rio Grande do Sul, Goiás. São Paulo, SP: Companhia Editora Nacional, 1940, v.3. (TEXTO). 
MORAES, Deodato de. Rumo ao campo. In: COSTA, Maria José Franco Ferreira de; SHENA, Denílson Roberta; SCHMDT, Maria Auxiliadora. I CONFERENCIA NACIONAL DE EDUCAÇÃO, Curitiba, 1927. Anais... Brasília, DF: INEP, 1997. p. 194-196. (TEXTO).

RIO GRANDE DO SUL. Lei n. 2.588, de 25 de janeiro de 1955. Organiza e fixa as bases do Ensino Normal no Rio Grande do Sul. (Biblioteca da Assembléia Legislativa - RS).

VARELA, Julia. Genealogia de la Escuela: análisis socio-historico del proceso de institucionalización de la escuela primaria. Tempora, Tenerife, n. 8, p. 13 - 44, jul./dez. 1986.

WERLE, Flávia Obino Corrêa. A Escola Rural: RGS, final do século XIX e início do XX. In: SEMINÁRIO DE PESQUISA EM EDUCAÇÃO DA REGIÃO SUL, 5. Curitiba. Anais... Curitiba: Anped Sul, 2004.

Recebido em: 16/08/2004 Aprovado em: 30/11/2004 